\title{
An Assessment on the Ultrasound Guided Dextrose Prolotherapy for Persistent Coccygeal Pain: A Case Series and Review of Literature
}

\section{Felix Linetsky ${ }^{1 *}$ and Francisco Torres $^{2}$}

${ }^{1}$ Department of Osteopathic Principles \& Practice, Clearwater FL, USA

${ }^{2}$ Florida Spine Institute, Clearwater FL, USA

As physicians practicing prolotherapy regularly, we read Dr. Yin Ting Chen et al. article with great interest. However, there are a number of issues raised that require further clarification.

Ultrasound guidance is a good tool for those who are not comfortable with palpation guided injection techniques. Dr. Hackett described his original case report on the treatment of persistent coccygeal pain with prolotherapy in the first edition of his textbook in 1956 (Case 19), and in the four subsequent editions, the latest published in 1991 [1-3]. Ever since the first publication, a large group of physicians have been using this treatment method.

The authors of the article published in this journal describe three cases of persistent coccydynia, successfully treated with ultrasound guided dextrose "prolotherapy." The first two patients had posttraumatic coccydynia with a definite tenderness to palpation of coccyx.

The third patient reported the sudden onset of back, bilateral leg, hip and tail bone pain, paresthesia to the left medial thigh down to the heel which was initially associated with incontinence. Three years later she had tenderness over the hips, posterior superior iliac spines, sacroiliac joints, Piriformis muscles and mid gluteal regions bilaterally. Palpation of the coccyx revealed minimal tenderness. From the description of the case it appears that she had low back pain with radiculopathy and referred coccydynia of unknown etiology. The authors described improvement of her coccydynia; however, it is not clear whether or not any of the remaining symptoms were resolved.

In none of the cases was a rectal exam performed or described with a direct palpation of the ventral coccyx. MRI studies were also not completed; therefore, it is impossible to know if there was any damage to the ligaments, cartilage of the sacrococcygeal joints or tendinosis of Coccygeus and Gluteus maximus muscles or bone marrow edema in these cases. Further ultrasound evaluation did not reveal abnormalities in the ligaments but what about the muscles? The Doppler study was not done, thus one cannot determine whether any neovascularity was present, which would signify the neurovascular ingrowth and partially explain pain in chronic tendinosis or ligamentosis. These unanswered questions suggest that the three cases described in the article belong in the category of coccydynia of unknown origin.

Dr. Hackett's original definition of prolotherapy describes the procedure as "the rehabilitation of incompetent structure by the generation of new cellular tissue." Classic applications for prolotherapy are painful hypermobility and ligament laxity. But the authors did not find any of these symptoms or any evidence of tissue compromise in the three cases they have described; therefore there was no indication for prolotherapy under the classical definition [2].

Collagenous connective tissues, despite slightly different biochemical content, blend at their boundaries and at the osseous structures, functioning as a single unit [4]. Ingrowth of small sensory and sympathetic fibers in degenerated connective tissue with release of the nociceptive substances is well described in the current literature.
Therefore, the denervation by any means is indicated to treat pain [4].

Ex juvantibus the treatment was successful, as in many cases described by Khan et al. [5] but the remaining questions are why it was successful and was it Prolotherapy?

Naming every hyperosmolar dextrose injection prolotherapy is arbitrary. In spinal anesthesia it is called a hyperosmolar or hyperbaric block, albeit smaller concentrations of dextrose are used.

It is not clear how: "In our case series, the use ultrasound allowed us to visually confirm the site of pathology..." where earlier in the text the authors write: "Ultrasound examination of her coccyx did not reveal any notable ligamentous and osseous abnormalities".

Experimental studies have demonstrated that any solution with osmolality greater than a $1000 \mathrm{mOsm} / \mathrm{l}$ is neurolytic, causing separation of the myelin lamellae in myelinated nerve fibers and total destruction in unmyelinated fibers, after soaking for one hour in solutions with osmolality greater than $1000 \mathrm{mOsm} / \mathrm{l}$ or distilled water. Pharmacologic properties of phenol, glycerin and hypertonic dextrose are both neurolytic and inflammatory. A 1:1 dilution of 50\% dextrose with $1 \%$ lidocaine as used by the authors produces a hyperosmolar $0.5 \%$ lidocaine with a $25 \%$ dextrose concentration and osmolality of $1388 \mathrm{mOsm} / \mathrm{l}$; (which is a hyperosmolar neurolytic block $[4,6]$.

In conclusion, the treatment described by Yin-Ting Chen, MD et al. falls into the category of hyperosmolar neurolytic blocks of the ingrown sensitive and sympathetic fibers detectable only by biopsy and special staining, but not into category of prolotherapy.

\section{References}

1. Hackett G (1956) Ligament and Tendon Relaxation: Treated by Prolotherapy (1stedn). Springfield

2. Hackett G (1958) Ligament and Tendon Relaxation: Treated by Prolotherapy. (3rdedn). Springfield

3. Hackett G, Hemwall G, Montgomery G. Ligament and Tendon Relaxation Treated by Prolotherapy. (5thedn). Gustav A, Hemwall MD. Publisher, Oak Park Illinois.

4. Linetsky F, Alfredson $H$, Crane D, Centeno C (2013) Treatment of Chronic Painful Musculoskeletal Injuries and Diseases with Regenerative Injection Therapy (RIT): Regenerative Injection Therapy Principles and Practice.

${ }^{*}$ Corresponding author: Felix Linetsky, Clinical Associate Professor Department of Osteopathic Principles \& Practice, 611 Druid Rd E, Clearwater FL 33756, USA, Tel: 727-787-5555; E-mail: Prolopain@aol.com

Received December 05, 2013; Accepted March 03, 2014; Published March 05 2014

Citation: Linetsky F, Torres F (2014) An Assessment on the Ultrasound Guided Dextrose Prolotherapy for Persistent Coccygeal Pain: A Case Series and Review of Literature. Altern Integ Med 3: 155. doi:10.4172/2327-5162.1000155

Copyright: $\odot 2014$ Linetsky F, et al. This is an open-access article distributed under the terms of the Creative Commons Attribution License, which permits unrestricted use, distribution, and reproduction in any medium, provided the original author and source are credited. 
Citation: Linetsky F, Torres F (2014) An Assessment on the Ultrasound Guided Dextrose Prolotherapy for Persistent Coccygeal Pain: A Case Series and Review of Literature. Altern Integ Med 3: 155. doi:10.4172/2327-5162.1000155

Page 2 of 2

5. Khan SA, Kumar A, Varshney MK, Trikha V, Yadav CS (2008) Dextrose prolotherapy for recalcitrant coccygodynia. Journal of Orthopaedic SurgeryHong Kong 16: 27.
6. Trescot A, Hansen H (2009) Neurolytic Agents: Pharmacology and Clinical Applications. Interventional Techniques in Chronic Non-Spinal Pain. 